\title{
Pain in Pig Production: Text Mining Analysis of the Scientific Literature
}

\author{
Barbara Contiero $^{1}$ (D) $\cdot$ Giulio Cozzi $^{1} \cdot$ Lee Karpf $^{1} \cdot$ Flaviana Gottardo $^{1}$
}

Accepted: 30 May 2019 / Published online: 7 June 2019

(c) The Author(s) 2019

\begin{abstract}
Public's concern about poor animal welfare provided by intensive farming systems has increased over the last decades. This study reviewed the interest of the scientific research on the pain issue in pig production to assess if the societal instances may be a driving force for the research activity. A literature search protocol was set up to identify the peer-reviewed papers published between 1970 and 2017 that covered the topic of 'pain in pigs' using Scopus ${ }^{\circledR}$, database of Elsevier@. One hundred and thirty papers were selected and they were mainly focused on the practice of castration (64\%) followed by tail docking (24\%). The scientific community first focused on these painful practices as a way to improve production efficiency and quality issues while more recently, due to the increased pressure by the public opinion, turned its interest towards the search of alternative solutions. A text mining analysis on the abstract of the selected papers clearly indicated the effort of the research to explore solutions to alleviate pain. Evocative words of this target were the selected terms 'pharmacological analgesic' and 'anaesthetic treatments'. The text mining highlighted vocalizations as the main pain indicators in pigs as this term was frequently associated to 'acute stress'. Ethical issues were a minor research topic in the scientific literature on pig breeding but in the short run, they are supposed to become a major subject to justify the acceptance of the modern production systems at the eyes of the consumers.
\end{abstract}

Keywords Animal welfare $\cdot$ Pig pain $\cdot$ Text mining $\cdot$ Scientific literature

Electronic supplementary material The online version of this article (https://doi.org/10.1007/s1080 6-019-09781-4) contains supplementary material, which is available to authorized users.

Barbara Contiero

barbara.contiero@unipd.it

1 Department of Animal Medicine, Production and Health, University of Padova, Viale dell’Università 16, 35020 Padua, Legnaro, Italy 


\section{Introduction}

The public policies in favour of cheaper food protein sources promoted a relevant change in the traditional animal production systems over the last 50 years. Efficiency in farm breeding has been achieved by intensification, but this evolution had a price paid largely by the animals (Sandøe et al. 2003). Ethical considerations concerning food of animal origin and public awareness of the way in which farm animals are kept in intensive production systems has increased over last decades (Appleby 1999). Nowadays, the main ethical issues relating to the animal food production chain are food safety, environmental impact of livestock production, use of biotechnology and antimicrobials to increase animal performance and last but not the least animal welfare (Bennett et al. 2002; Scholten et al. 2013). Animal welfare, food safety, taste, flavour and price are principal attributes that consumers use to assess and choose food products of animal origin. The European Commission has conducted repeated surveys on a large sample of EU citizens to understand their meaning of farm animal welfare, providing valuable material for comparative analyses (European Commission 2016). Main findings of these surveys were that Europeans have two different opinions; someone considers farm animal welfare as "the duty to respect all animals" while for some others it means "the way animals are treated, providing them with a better quality life". In this contest, people tend to believe that better animal rearing conditions will provide better and safer food (Frewer et al. 2005). Consumers and citizens expressed their worry about certain livestock production systems and these complain fostered the EU to draft specific legislations to improve living conditions of several farm animal categories, such as veal calves, laying hens and pigs (De Roest et al. 2010). Animal welfare legislation has evolved in accordance with citizens' expectations and market demands. A corner stone of the legislation excursus was the Council Directive 98/58/EC (2008), which provided basic rules for farm animals. The rules reflected the so-called 'Five Freedoms': freedom from hunger and thirst; freedom from discomfort; freedom from pain, injury and disease; freedom to express normal behaviour; freedom from fear or distress (Brambell 1965). A further step forward was the Lisbon Treaty in 2009, which acknowledged animals as sentient beings, paving the way for the development of a common 'Strategy for the protection and welfare of the animals' (2012-2015)

Animal welfare concerns are widespread not only in EU but in the entire world. According to Hynes (2008) the emerging ethical issue about livestock farming in the US was not transferred from the concern regarding companion and lab animals since the public opinion was not fully aware of the current intensive rearing conditions and how they affect the animals subjected to them. The request for welfare regulations emerged only when the society became aware of the substitution of the traditional extensive production systems by the new intensive ones. In an online survey of 798 U.S. households, $14 \%$ of respondents reported reduction in pork consumption due to welfare concerns with an average drop of $56 \%$ from their previous consumption (Mckendree et al. 2014). According to the same survey, the reduction in pork consumption was larger than that found for other livestock food products. 
Within the farm animal welfare topic, there is an increased awareness towards the farm practices that can inflict pain to the animal (Tawse 2010). Animal pain is an aversive sensory and emotional experience expressing an awareness by the animal of damage or threat to the integrity of its tissues; it changes the animal's physiology and behaviour to reduce or avoid damage, to reduce the likelihood of recurrence and to promote recovery (Molony and Kent 1997). Several painful practices are routinely performed in pig farms either to reduce the risk of some harmful behaviours among pen-mates or to lower some detrimental effects on meat quality. Tail docking enables producers to limit the occurrence of tail biting and its consequent negative welfare and economic impacts (D'Eath et al. 2016). Tail biting has a welfare impact in terms of immediate pain for the victims and injured tails become a target for infections resulting in further suffering. Moreover, it may lead to partial or total carcass damage and consequent economic loss for producers. Teeth resection is supposed to reduce injures to the littermates as well as to the sow during suckling (Gallois et al. 2005). Pig castration should avoid the occurrence of undesired behaviours such as mounting and aggressions, preventing a serious meat quality alteration such as 'boar taint' (Leeb et al. 2014). Ear tagging/notching is performed for animal's identification and traceability purposes (Leslie et al. 2010). Injections are performed for vaccinations or to prevent specific deficiencies such the iron one. Most of these painful practices are performed on new born animals within the first week of life because it was believed that neonates do not suffer from pain due to the immaturity of their neural development. However, research on humans (Anand 1990; Andrews and Fitzgerald 1994) demonstrated that neonates can suffer from pain despite their endogenous mechanisms of pain control is not functional. Similarities in anatomy (pain system), physiology (pain sensation) and behaviour (pain expression) between human and other mammals, support the assumptions that the perception of pain in young farm mammals can be analogue to that of humans (Anil et al. 2002).

As the societal instances may be a driving force for the research activity, we reviewed the interest of the scientific research around the concept of pain in pigs. So far, several studies dealing with pain in pigs have been published, but it is difficult and time-consuming task to extract and understand the main information from these cumulated collections. Review articles usually perform a literature meta-analysis on a specific issue, while text mining, a process of deriving patterns and trends from texts, can be used as an alternative approach to gain a broad understanding of an entire dataset and to explore its dynamics. This study performed a text mining analysis on the existing scientific literature dealing with pain in pigs in order to find out hidden associations between painful practices and alternative treatments as well as the proposed methods to assess pain in pigs.

\section{Materials and Methods}

A literature search protocol was set up to identify the peer-reviewed papers that covered the topic of 'pig pain' using Scopus ${ }^{\circledR}$, the abstracts and citation database of Elsevier@. These key-words were used considering the publication years from 1970 to 2017. The key-words were searched in article title, abstract, and 
keywords fields. The search was performed in January 2018 and produced 455 records, which were then read and submitted to a further manual screening to exclude irrelevant records. Reasons for paper exclusion were: pharmacological and experimental models, other species, laboratory animals, general swine welfare, general animal welfare, slaughtering and euthanasia, clinical cases, parasitic and infectious diseases, no abstract available for the paper.

An electronic Excel workbook was used to collect the data extracted from the retained papers. The spreadsheet was built in a 2-way table format considering every paper (record) as a row and its descriptive information in columns. A complete list of these descriptors together with additional information on data format are schematically reported as Supplementary material. Some descriptive statistics of the selected papers were calculated to profile the scientific corpus. Additional information regarding the subject area and the quartile of the scientific journal ranking of the selected papers were recorded from SCImago database. A text mining analysis was performed on the abstracts of the selected papers to find important patterns in text data. This technique converts the text into a numeric information, studies the word frequency distributions and the association between most frequent words. According to Sebastiani (2002), the following pre-processing steps of text were performed:

1. Exclusion of certain characters: punctuation, blanks and numerical digits.

2. Exclusion of "stop words": certain common words such as "the", "and", "a", "of". These words are used in the language very frequently, but communicate very little unique information about the contents of the document. In addition, pain and pig were also removed from the dataset to avoid poor discriminative information due to their presence in almost all abstract retrieved.

3. Application of stemming algorithm: a reduction of words to their roots (tokenization), to avoid the count of the same word with different grammatical forms (example: "veterinar" is the root of the words veterinary, veterinarian, veterinarians and so on).

After the pre-processing steps, texts were splitted into tokens. Token is a meaningful unit of text. In this analysis, tokens detected were not only single words but also bi-grams, that are pairs of consecutive words. The tokens were organized into a matrix that contains the documents along the rows and the terms along the columns (so-called document-term matrix). A term frequency- inverse document frequency technique (TFIDF) was used to weight the words (Salton and Buckley 1988). It represents the frequency of a term adjusted for how widely it is used. This aims at reflecting how important a word is in the whole collection of documents. The words, which have the great impact (TFIDF $\geq 0.40$ ), were represented as histogram and cloud (https://www.wordclouds.com/). Correlations among the most weighted terms in the document-term matrix were calculated and those higher than a correlation threshold $(r)>0.60$ were presented (Feinerer et al. 2008).The analysis was conducted with $\mathrm{R}$ package (2017), using libraries: tm, stringr, Snowball3. 


\section{Results}

\section{Profiles of Selected Papers}

One hundred and thirty out of 455 abstracts (28.5\%) retrieved and downloaded from Scopus ${ }^{\circledR}$, had pain in pig as relevant topic and were retained for analysis. Pharmacological and experimental models represented the most frequent reason for discharge ( $27 \%$ of the total excluded papers). Fifteen papers contained the term 'ethic' in title, keywords or abstract but 11 of them dealt with general welfare issue in pigs and therefore were not retained. Research articles represented the most common type of retained paper $(83 \%)$ followed by reviews $(9 \%)$, conference papers $(6 \%)$ and others $(2 \%)$. Prevalent publishing sources of the retained papers were scientific journals dealing with animal welfare and farm animal production whereas the journals addressed to veterinary science were a minor publishing channel (16\%). According to the SCImago journal ranking, $53 \%$ of the papers were published on journals included in the first quartile (Q1) and $19 \%$ on Q2 journals. The responsible research institutions of the articles were mainly located in Europe (66\%) followed by North America (22\%). The Fig. 1 shows the increase in the number of the papers regarding the topic according to the year of publication. As a whole, the 130 articles collected a total of 1996 citations (Fig. 1).The most cited article was published in 1998 collecting 117 citations followed by an article published in 2006 that collected 111 citations (Table 1). Castration was the topic of the most cited articles (Table 1).

As reported in Table 2, five out of seven pain sources discussed in the selected papers were practices performed on piglets in intensive rearing systems. Castration was the main cause of pain addressed in the selected papers (64\% of the total documents), followed by tail docking (24\%) and ear tagging (11.5). Only two causes of pain (lameness and farrowing stress) specifically addressed adult animals (especially

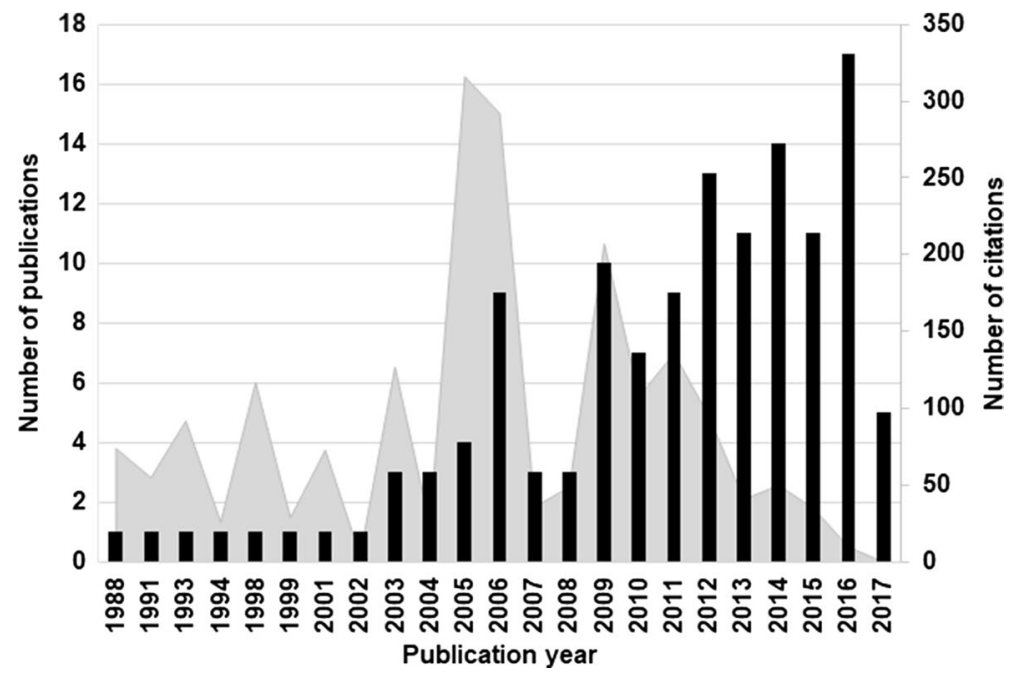

Fig. 1 Number of paper (black histogram) and citations (grey profile) per publication years 
Table 1 The ten most cited articles dealing with pain in pig by topic, publication year, journal quartile (referred to the publication year) and subject area of the journal

\begin{tabular}{|c|c|c|c|c|c|}
\hline Article & Citations & Topics & Publication year & Journal quartile & Journal subject area \\
\hline 1 & 117 & Castration & 1998 & Q2 & $\begin{array}{l}\text { Animal science and } \\
\text { zoology }\end{array}$ \\
\hline 2 & 111 & Castration & 2006 & Q2 & $\begin{array}{l}\text { Animal science and } \\
\text { zoology }\end{array}$ \\
\hline 3 & 103 & Castration & 2006 & Q2 & $\begin{array}{l}\text { Animal science and } \\
\text { zoology }\end{array}$ \\
\hline 4 & 99 & $\begin{array}{l}\text { Castration, tail } \\
\text { docking, teeth } \\
\text { resection }\end{array}$ & 2005 & Q1 & $\begin{array}{l}\text { Animal science and } \\
\text { zoology }\end{array}$ \\
\hline 5 & 96 & Castration & 2005 & Q1 & $\begin{array}{l}\text { Animal science and } \\
\text { zoology }\end{array}$ \\
\hline 6 & 95 & Castration & 2003 & Q1 & $\begin{array}{l}\text { Animal science and } \\
\text { zoology }\end{array}$ \\
\hline 7 & 92 & Castration & 1993 & Q1 & $\begin{array}{l}\text { Animal science and } \\
\text { zoology }\end{array}$ \\
\hline 8 & 74 & Castration & 1988 & Q1 & $\begin{array}{l}\text { Animal science and } \\
\text { zoology }\end{array}$ \\
\hline 9 & 73 & Castration & 2001 & Q2 & $\begin{array}{l}\text { Animal science and } \\
\text { zoology }\end{array}$ \\
\hline 10 & 63 & Castration & 2005 & Q1 & Veterinary \\
\hline
\end{tabular}

Table 2 Percentage of articles that discussed the indicated pain source

\begin{tabular}{ll}
\hline Pain source & $\begin{array}{l}\text { Percentage of } \\
\text { articles (\%) }\end{array}$ \\
\hline Castration & 64.6 \\
Tail docking & 23.8 \\
Ear tag & 11.5 \\
Teeth resection & 8.5 \\
Lameness & 6.9 \\
Farrowing stress & 6.1 \\
Vaccination/injection & 5.4 \\
\hline
\end{tabular}

sows) and as a whole, they represented only a lower percentage (13\%) of the pain topics discussed in the selected collection.

\section{Text Mining}

The pre-processing of the data produced 16,381 tokens and after a process of reduction of sparseness (exclusion of the 'rare words'), 3093 tokens were retained. Figure $2 \mathrm{a}$ shows the most impactful tokens with a TFIDF weight $\geq 0.40$. Castration had the highest TFIDF (0.98), followed by 'tail' (0.96) and 'sows' (0.95). In Fig. 2b, the TFIDF weight of the tokens is proportional to their font size in the cloud. The real 


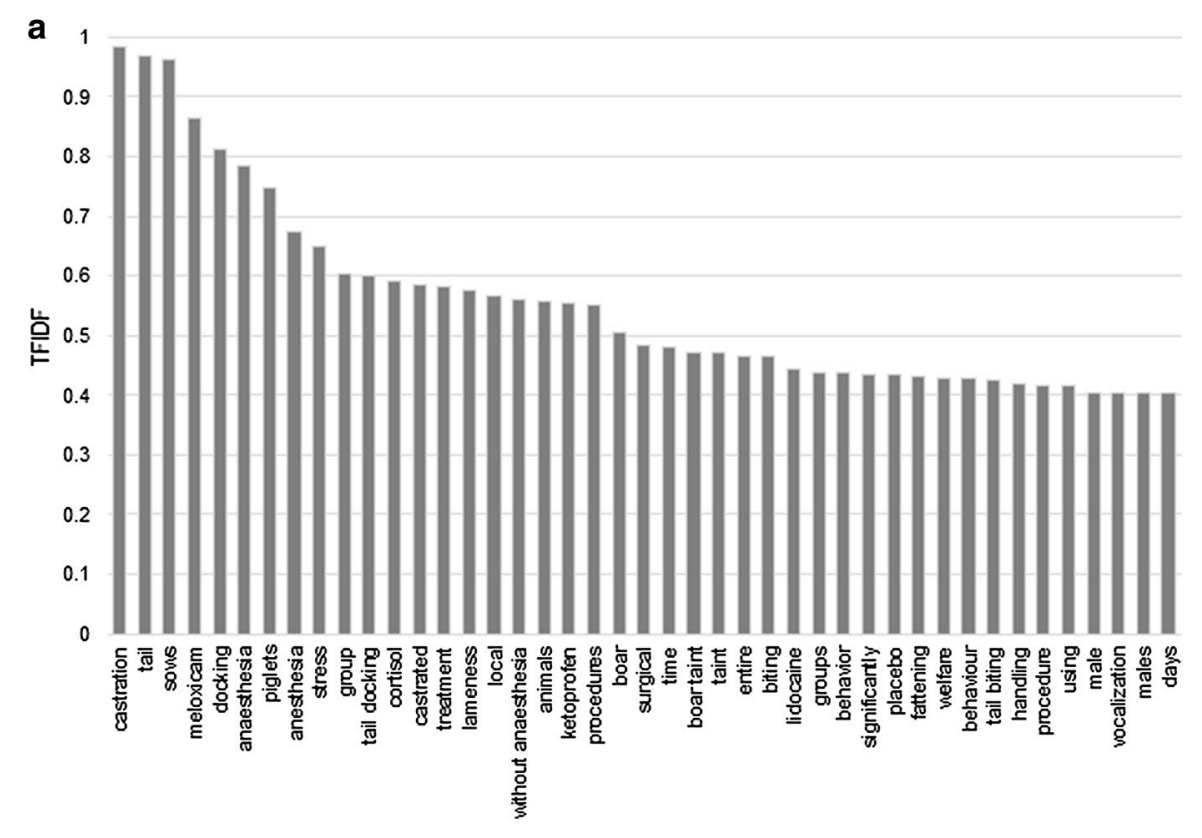

b

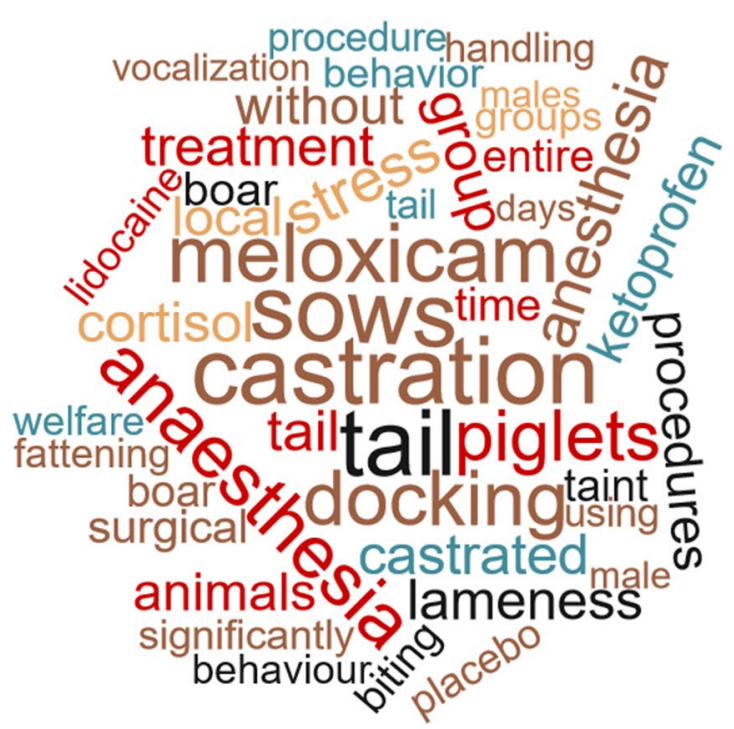

Fig. 2 Most impactful tokens (TFIDF $\geq 0.4$ ). a Histogram, b cloud

impact of the terms 'anaesthesia' and 'anesthesia' should be greater, because they have the same meaning but different spelling: as the British English prefers anaesthesia whereas North America prefers anesthesia. A similar situation concerns the words behaviour/behavior. Among the behaviour indicators of pain, the text mining 
selected vocalization as most weighted term (TFIDF $=0.40)$. In case of bi-grams, tokens with TFIDF $\geq 0.4$ were: tail docking (0.60), without anaesthesia (0.56), boar taint (0.47), tail biting (0.42) (Fig. 2a). The most relevant and meaningful association between terms (i.e. terms that correlate) are reported in Table 3.

\section{Discussion}

The attitude of the consumers towards modern farm animal production systems is mostly negative since they are considered not fully capable to provide two core concepts for a good animal welfare such as naturalness and humane treatment (Clark et al. 2016). Animal welfare remains central for the public opinion and general concerns have been raised about pigs' quality of life including absence of pain, suffering and mistreatments (Sato et al. 2017). However, several studies revealed that consumers had low levels of awareness about the occurrence of painful practices in pigs (Heid and Hamm 2012; Vanhonacker et al. 2012). Moreover, individuals may assume different attitudes depending on their role as citizens or consumers (Clark et al. 2016). As citizens, they take care about modern production systems in order to have animal welfare friendly products; as consumers, they have other priorities when they purchase foods. This could partly justify the fact that the analyzed publications consider the painful practices as a tool still needed to achieve specific production standards required by the industry and/or market. A relevant example at this regard is the practice of castration that is performed to avoid the occurrence of "boar taint" as well as to reduce mounting and aggressions following the onset of puberty (Morales et al. 2017). Castration of piglets without pain relief is a common practice in swine production (Heid and Hamm 2012) despite research demonstrated that surgical practice without analgesia induces endocrine and behavioural responses linked with pain (Prunier et al. 2006; Lonardi et al. 2015). In our study, pain in pigs was a relevant topic for a relatively small percentage of extracted papers (28\%) and only $3 \%$ contained the term 'ethic' in title, abstract or keywords showing that ethical

Table 3 Associations between terms (tokens) with $r>0.60$

\begin{tabular}{lll}
\hline Term & Term & $\begin{array}{l}\text { Association } \\
\text { coefficient }\end{array}$ \\
\hline Ketoprofen & Problem sows & 0.81 \\
Ketoprofen & Lameness assessed & 0.81 \\
Ketoprofen & Improve welfare & 0.66 \\
Lameness & Lame-sows & 0.70 \\
lidocaine & Castration & 0.66 \\
Stress & Acute stress & 0.73 \\
Stress & Moderate stress & 0.73 \\
Stress & Stress piglets & 0.73 \\
Stress & Animal vocalization & 0.62 \\
Vocalization & Acute stress & 0.62 \\
Welfare & Animal welfare & 0.70 \\
\hline
\end{tabular}


issues are still a minor research topic in pig breeding. However, the interest by the scientific community has grown particularly in recent years as the number of papers published in the last 10 years was about three times greater than the number of articles published from 1998 to 2007 (100 vs. 30). The greatest share of the papers about pain in pigs involved European research institutions and in the EU countries support to the increased number of papers published from 2008 to 2017 surely came from the implementation of the Council directive for the protection of pigs (2008) as well as from other initiatives of the European Commission (2010). The topic of pain in pigs found high ranked dissemination channels in the scientific community, since more than a half of the selected papers were published in Q1 journals.

The increased pressure by the public opinion against painful practices on farm animals has certainly stimulated the response of the scientific world towards the identification of alternative practices. Scientific evidences demonstrated that mutilations could be avoided by appropriate and enriched environments as well as by an improved management and nutrition. Tail docking is still performed to reduce the risk and severity of tail biting among piglets (Sutherland and Tucker 2011; D'Eath et al. 2016; Scollo et al. 2016). In many farms, this painful mutilation masks the real causes behind the occurrence of aggressive behaviours between littermates represented by a suboptimal rearing environment in which piglets cannot fulfil their behavioural needs such as rooting, chewing and foraging (Valros and Heinonen 2015; Scollo et al. 2017).

Literature review is a critical way of understanding the current state of a given topic, providing some direction for further studies. However, it usually focus on a single specific issue. Text mining is an alternative approach for information retrieval when dealing with a large number of documents (Wang et al. 2016). In this study, the text mining analysis suggested the complexity of the pain issue and its correlation with welfare in pigs. The outcomes indicated the effort of the research to explore solutions to alleviate pain. Evocative words of this target are the pharmacological analgesic and anaesthetic treatments such as meloxicam, ketoprofen, nonsteroidal anti-inflammatory drugs, and lidocaine that were selected among terms with TFIDF $\geq 0.40$. Analgesia should be used to prevent pain in castrated piglets as recommended by European Food Safety Authority (2004). Interest toward analgesic treatments in the scientific corpus selected by the text mining demonstrated the effort of the research to find analgesic solution alternative to anaesthesia, which has numerous drawbacks in cost, time consuming, problems of safety for animals and people. As suggested by the association among tokens, lidocaine was related mainly with castration (0.66) because it is used to avoid pain during the procedure, whereas 'ketoprofen' with lameness (in sows, 0.81) for its pain reliever action.

Consistent with the most updated farm animal welfare assessment schemes that avoid the use of the invasive animal-based measures (Welfare Quality ${ }^{\circledR}$ project: http://www.welfarequality.net/en-us/home/; AWIN: https://cordis.europa.eu/proje $\mathrm{ct} / \mathrm{rcn} / 99394 /$ reporting/en), results of text mining indicated that there is an effort to assess pain in pigs by using not invasive indicators. This was suggested by the high frequency of the term 'behaviour'. Behavioural indicators are not invasive as well as not intrusive as they do not disturb the animal during recording. Vocalizations, one of the most impactful words highlighted by the text mining, are the main pain 
indicators in pigs (da Silva Cordeiro et al. 2013; Ison et al. 2016). The association among tokens showed the term 'vocalization' being related to 'acute stress', meaning that very frequently the two concepts were reported together in the analysed texts.

The dominating feature in the twentyfirst century in most areas of human activities is the excess of available information which often lacks proper scrutiny regarding scientific validity. Stakeholders and interested parties in animal welfare operate in an environment with conflicting interests and limited opportunities for common approaches to be guided by sound science. Nowadays, it is important that science provides answers to the questions raised by society and gives clear and transparent advices to politicians as well as to participants in the public debate (Sandøe et al. 2003). At this regard, the outcomes of the text mining analysis highlighted the evolution of the scientific research on the topic of pain in pigs that moved from aspects focused on production efficiency towards the search for alternative painless practices.

Along with the safety and environmental sustainability, the ethical issue going to become a mandatory requirement of the modern livestock production systems in order to justify their existence at the eyes of the public opinion. If this issue is addressed in a clear way, it may be possible not only to advance the use of science to improve the welfare of farm animals but also to improve the public dialogue about how animals are being treated in the production of food.

\section{Conclusion}

Text mining analysis of the scientific literature has shown a growing interest on painful practices in pigs that reflects the concerns of the public opinion and the legislation. It suggested the complexity of the pain issue and its association with productive and quality targets. The increased pressure by the public opinion against painful practices on farm animals stimulated a response of the scientific world towards the identification of alternative solutions capable to mitigate the pain in pigs particularly by the use of pharmacological treatments. The analysis of the scientific literature showed that ethical issues were still a minor research topic in pig breeding but they are supposed to become major subject to justify the acceptance of the modern production systems at the eyes of the consumers.

Open Access This article is distributed under the terms of the Creative Commons Attribution 4.0 International License (http://creativecommons.org/licenses/by/4.0/), which permits unrestricted use, distribution, and reproduction in any medium, provided you give appropriate credit to the original author(s) and the source, provide a link to the Creative Commons license, and indicate if changes were made.

\section{References}

Anand, K. J. (1990). Neonatal stress responses to anesthesia and surgery. Clinics in Perinatology, 17(1), 207-214. 
Andrews, K., \& Fitzgerald, M. (1994). The cutaneous withdrawal reflex in human neonates: Sensitization, receptive fields, and the effects of contralateral stimulation. Pain, 56(2), 95-101. https://doi. org/10.1016/0304-3959(94)90154-6.

Anil, S. S., Anil, L., \& Deen, J. (2002). Challenges of pain assessment in domestic animals. Journal of the American Veterinary Medical Association, 220(3), 313-319. https://doi.org/10.2460/javma .2002.220.313.

Appleby, M. C. (1999). What should we do about animal welfare?. Oxford: Blackwell Science Ltd.

Bennett, R. M., Anderson, J., \& Blaney, R. J. P. (2002). Moral intensity and willingness to pay concerning farm animal welfare issues and the implications for agricultural policy. Journal of Agricultural and Environmental Ethics, 15(2), 187-202. https://doi.org/10.1023/A:1015036617385.

Brambell, F. W. R. (1965). Report of the technical committee to enquire into the welfare of animals kept under intensive husbandry conditions. London: Her Majesty's Stationery Office.

Clark, B., Stewart, G. B., Panzone, L. A., Kyriazakis, I., \& Frewer, L. J. (2016). A systematic review of public attitudes, perceptions and behaviours towards production diseases associated with farm animal welfare. Journal of Agricultural and Environmental Ethics, 29, 455-478. https://doi. org/10.1007/s10806-016-9615-x.

Council Directive 2008/120/EC. (2008). Laying down minimum standards for the protection of pigs. Official Journal of the European Union, 47, 5-13.

D'Eath, R. B., Niemi, J. K., Vosough Ahmadi, B., Rutherford, K. M. D., Ison, S. H., Turner, S. P., et al. (2016). Why are most EU pigs tail docked? Economic and ethical analysis of four pig housing and management scenarios in the light of EU legislation and animal welfare outcomes. Animal, 10(4), 687-699. https://doi.org/10.1017/S1751731115002098.

da Silva Cordeiro, A. F., de Alencar Nääs, I., Oliveira, S. R. M., Violaro, F., de Almeida, A. C. M., \& Neves, D. P. (2013). Understanding vocalization might help to assess stressful conditions in piglets. Animals, 3(3), 923-934. https://doi.org/10.3390/ani3030923.

De Roest, K., Ferrari, P., Montanari, C., Bokma, M., Heutinck, L., van Reenen, K., et al. (2010). Report on consumers' attitudes towards animal welfare standards based on the main findings of EU and national research projects. Resource document. https://cordis.europa.eu/project/rcn/87806/repor ting/en. Accessed November 1, 2018.

EU Commission. (2010). European declaration on alternatives to surgical castration of pigs. Resource document. https://ec.europa.eu/food/sites/food/files/animals/docs/aw_prac_farm_pigs_cast-alt_ declaration_en.pdf. Accessed August 1, 2018.

European Commission. (2016). Attitudes of Europeans towards animal welfare. Special Eurobarometer. https://doi.org/10.2875/884639.

European Food Safety Authority. (2004). Welfare aspects of the castration of piglets. EFSA Journal, 91, 1-18.

Feinerer, I., Hornik, K., \& Meyer, D. (2008). Text mining infrastructure in R. Journal of Statistical Software, 25(5), 1-54. https://doi.org/10.18637/jss.v025.i05.

Frewer, L. J., Kole, A., van de Kroon, S. M., \& de Lauwere, C. (2005). Consumer attitudes towards the development of animal-friendly husbandry systems. Journal of Agricultural and Environmental Ethics, 18(4), 345-367. https://doi.org/10.1007/s10806-005-1489-2.

Gallois, M., Le Cozler, Y., \& Prunier, A. (2005). Influence of tooth resection in piglets on welfare and performance. Preventive Veterinary Medicine, 69(1), 13-23. https://doi.org/10.1016/j.preve tmed.2004.12.008.

Heid, A., \& Hamm, U. (2012). Consumer attitudes towards alternatives to piglet castration without pain relief in organic farming: qualitative results from Germany. Journal of Agricultural and Environmental Ethics, 25(5), 687-706. https://doi.org/10.1007/s10806-011-9350-2.

Hynes, R. P. (2008). Rollin's theory of animal welfare and its ethical implications. In R. P. Haynes (Ed.), Animal welfare (pp. 79-85). Dordrecht: Springer.

Ison, S. H., Clutton, R. E., Di Giminiani, P., \& Rutherford, K. M. D. (2016). A review of pain assessment in pigs. Frontiers in Veterinary Science, 3, 108. https://doi.org/10.3389/fvets.2016.00108.

Leeb, C., Hegelund, L., Edwards, S., Mejer, H., Roepstorff, A., Rousing, T., et al. (2014). Animal health, welfare and production problems in organic weaner pigs. Organic Agriculture, 4(2), 123-133. https ://doi.org/10.1007/s13165-013-0054-y.

Leslie, E., Hernández-Jover, M., Newman, R., \& Holyoake, P. (2010). Assessment of acute pain experienced by piglets from ear tagging, ear notching and intraperitoneal injectable transponders. Applied Animal Behaviour Science, 127(3-4), 86-95. https://doi.org/10.1016/j.applanim.2010.09.006. 
Lonardi, C., Scollo, A., Normando, S., Brscic, M., \& Gottardo, F. (2015). Can novel methods be useful for pain assessment of castrated piglets? Animal, 9(5), 871-877. https://doi.org/10.1017/S1751 731114003176.

Mckendree, M. G. S., Croney, C. C., \& Widmar, N. J. O. (2014). Effects of demographic factors and information sources on United States consumer perceptions of animal welfare. Journal of Animal Science, 21, 3161-3173. https://doi.org/10.2527/jas.2014-6874.

Molony, V., \& Kent, J. E. (1997). Assessment of acute pain in farm animals using behavioral and physiological measurements. Journal of Animal Science, 75(1), 266-272.

Morales, J., Dereu, A., Manso, A., de Frutos, L., Piñeiro, C., Manzanilla, E. G., et al. (2017). Surgical castration with pain relief affects the health and productive performance of pigs in the suckling period. Porcine Health Management, 3(1), 18. https://doi.org/10.1186/s40813-017-0066-1.

Prunier, A., Bonneau, M., von Borell, E. H., Cinotti, S., Gunn, M., Fredriksen, B., et al. (2006). A review of the welfare consequences of surgical castration in piglets and the evaluation of non-surgical methods. Animal Welfare, 15, 277-289. https://doi.org/10.1063/1.2472368.

R Core Team. (2017). R: A language and environment for statistical computing. R Foundation for Statistical Computing, Vienna, Austria. http://www.R-project.org/. Accessed Aug 2018.

Salton, G., \& Buckley, C. (1988). Term-weighting approaches in automatic text retrieval. Information Processing and Management, 24(5), 513-523. https://doi.org/10.1016/0306-4573(88)90021-0.

Sandøe, P., Christiansen, S. B., \& Appleby, M. C. (2003). Farm animal welfare: The interaction of ethical questions and animal welfare science. Animal Welfare, 12, 469-478.

Sato, P., Hötzel, M. J., \& Von Keyserlingk, M. A. G. (2017). American citizens' views of an ideal pig farm. Animals, 7, 64. https://doi.org/10.3390/ani7080064.

Scholten, M. C. T., De Boer, I. J. M., Gremmen, B., \& Lokhorst, C. (2013). Livestock farming with care: Towards sustainable production of animal-source food. NJAS-Wageningen Journal of Life Sciences, 66, 3-5. https://doi.org/10.1016/j.njas.2013.05.009.

Scollo, A., Contiero, B., \& Gottardo, F. (2016). Frequency of tail lesions and risk factors for tail biting in heavy pig production from weaning to $170 \mathrm{~kg}$ live weight. Veterinary Journal, 207, 92-98. https:// doi.org/10.1016/j.tvj1.2015.10.056.

Scollo, A., Gottardo, F., Contiero, B., \& Edwards, S. A. (2017). A cross-sectional study for predicting tail biting risk in pig farms using classification and regression tree analysis. Preventive Veterinary Medicine, 146, 114-120. https://doi.org/10.1016/j.prevetmed.2017.08.001.

Sebastiani, F. (2002). Machine learning in automated text categorization. ACM Computing Surveys, 34(2), 1-47. https://doi.org/10.1145/505282.505283.

Sutherland, M. A., \& Tucker, C. B. (2011). The long and short of it: A review of tail docking in farm animals. Applied Animal Behaviour Science, 135, 179-191. https://doi.org/10.1016/j.appla $\operatorname{nim} .2011 .10 .015$.

Tawse, J. (2010). Consumer attitudes towards farm animals and their welfare: A pig production case study. Bioscience Horizons, 3(2), 156-165. https://doi.org/10.1093/biohorizons/hzq020.

Valros, A., \& Heinonen, M. (2015). Save the pig tail. Porcine Health Management, 1, 2. https://doi. org/10.1186/2055-5660-1-2.

Vanhonacker, F., Verbeke, W., van Poucke, E., Pieniak, Z., Nijs, G., \& Tuyttens, F. (2012). The concept of farm animal welfare: Citizen perceptions and stakeholder opinion in Flanders, Belgium. Journal of Agricultural and Environmental Ethics, 25(1), 79-101. https://doi.org/10.1007/s10806-010-9299-6.

Wang, S. H., Ding, Y., Zhao, W., Huang, Y. H., Perkins, R., Zou, W., et al. (2016). Text mining for identifying topics in the literatures about adolescent substance use and depression. BMC Public Health, 16, 279. https://doi.org/10.1186/s12889-016-2932-1.

Publisher's Note Springer Nature remains neutral with regard to jurisdictional claims in published maps and institutional affiliations. 